\title{
Home Monitoring of Blood Pressure: Patients' Perception and Role of the Pharmacist
}

\author{
Iman A Basheti* and Ayman Khdair \\ Department of Clinical Pharmacy \& Therapeutics, Faculty of Pharmacy, Applied Science University, Amman, Jordan
}

*For correspondence: Email: dr_iman@asu.edu.jo; Tel: +962 799048 003; Fax: +9626 5515017

Received: 4 December 2013

Revised accepted: 10 September 2014

\begin{abstract}
Purpose: To explore the use of the blood pressure monitors by hypertensive patients in Jordanian homes and investigate their effect on emotional status and disease management, and the role of the pharmacist in this regard.

Methods: This cross-sectional study was conducted over two months in 2012, in Amman, Jordan. Participants visiting cardiovascular clinics were approached and asked to answer a validated questionnaire. One hundred patients with doctor-diagnosed hypertension were recruited into the study. The questionnaire investigated the role of the pharmacist regarding the use of the blood pressure home measuring devices, patients' emotional response to their blood pressure readings and actions taken in response. Completed questionnaires were encoded and the data were analyzed using SPSS (version 17).

Results: A majority of the patients (82\%) use home measuring monitors to monitor their blood pressure at home. The pharmacist was reported as the health care professional mostly responsible for counseling patients on the proper use of blood pressure monitors (50\%) and delivering needed relevant education (56 \%). A majority of participants suffer from anxiety (68\%) in response to high blood pressure readings. The main follow-up management performed by participants in response to elevated blood pressure was physical activity (40\%).

Conclusion: Most hypertensive patients in Jordan use home blood pressure monitors; however, home self-measurement showing high blood pressure readings cause many patients to feel anxious. Pharmacists take the lead in educating patients in this regard.
\end{abstract}

Keywords: Jordan, Hypertension, Blood pressure monitor, Pharmacist

Tropical Journal of Pharmaceutical Research is indexed by Science Citation Index (SciSearch), Scopus, International Pharmaceutical Abstract, Chemical Abstracts, Embase, Index Copernicus, EBSCO, African Index Medicus, JournalSeek, Journal Citation Reports/Science Edition, Directory of Open Access Journals (DOAJ), African Journal Online, Bioline International, Open-J-Gate and Pharmacy Abstracts

\section{INTRODUCTION}

Hypertension is a chronic condition affecting approximately one billion individuals worldwide [1]. In Jordan, the prevalence of hypertension is very high approaching $16 \%$ [2]. The World Health Organization lists Jordan as one of the Eastern Mediterranean Region countries with cardiovascular diseases being the most challenging health problem mainly caused by hypertension[3]. The latest report published by the Jordanian Ministry of Health stated hypertension as the third most prevalent cause of death in both men and women [4]. Family history, stressful lifestyle, aging population, smoking and alcohol drinking causing atherosclerotic changes are common predisposing factors to hypertension $[5,6]$.

Only $30 \%$ of patients with hypertension were reported to have controlled blood pressure values [2]. One of the main ways to manage 
hypertension is by using the blood pressure home measuring monitors. They have been available for more than 30 years with various research supporting their predictive ability on the clinical outcomes of the disease $[7,8]$. They have been associated with lower cost [9], less bias by the observer, less white coat effects, better correlation with daytime values of ambulatory measurements [10], and identifies masked hypertension that is higher outside of the clinic [11].

The aim of this study is to explore the use of blood pressure home measuring monitors by hypertensive patients in Jordanian homes, role of the pharmacist, and effect of monitors use on patients' disease management and emotional status.

\section{EXPERIMENTAL}

This cross-sectional study was conducted in 2012 in Jordan. The study was carried out over a period of two months (October and November 2012). Participants visiting cardiovascular clinics at Jordan University hospital were approached for participation in the study. The researcher approached the patients between 9 am and $5 \mathrm{pm}$ during working days of the week (Sunday to Thursday). Inclusion criteria included age above 18, doctor diagnosis of hypertension, using antihypertensive medications for at last 6 months and speaking Arabic. Exclusion criteria involved presence of any mental disorder or being involved in another clinical trial. Participants who agreed to take part in the study provided informed oral consents.

The questionnaire was self-reported and included two parts, the first part investigated participants' demographic information. The second part assessed the participants' health status using questions about their condition diagnosis, level of control, the use of home measuring monitors to monitor their blood pressure, their response regarding different readings, and the impact of using such monitors on their psychological status. The questionnaire included questions to investigate patients' dependence on the different health care professionals to educate them regarding the proper use of the monitors and to discuss their readings.

To ensure face validity, the questionnaire was evaluated by all academics that have a previous experience in conducting clinical studies and have a wide range of clinical professional experience. The questionnaire was then completed by randomly selected hypertensive patients $(n=10)$ to test for clarity of questions. Views and comments of the patients were considered by the researchers and then incorporated where appropriate into the final version of the questionnaire. To assess testretest reliability, the questionnaire was administered on two occasions to 15 randomly selected hypertensive patients. The second testing took place two weeks after the first one, and was not included in the final survey analysis. Test retest reliability was calculated using Spearman's correlation coefficient (r).

Completed questionnaires were inserted in envelops by the researcher and returned for data entry and analysis.

\section{Data analysis}

Participants' responses were encoded and the data were analyzed using Statistical Package for the Social Sciences (SPSS, version 17, Chicago, IL, US). Descriptive analysis was carried out to determine proportions for categorical data. Chi square test was used to identify any significant difference among the participants' responses, with significance defined as $p$-value of $\leq 0.05$.

Sample size calculation was based on the population of Amman (1,206,266 in the year 2010) [12], with a $16 \%$ prevalence of hypertension (193002) [2], a sample size of 377 was calculated, for a margin error of $5 \%$, confidence level of $95 \%$, and a response distribution of $50 \%$.

\section{RESULTS}

The questionnaire was successfully validated for 'test-retest reliability', as results gave a rho-value of 0.88 , indicating acceptable reliability.

During the two months period of the study, four hundred and eight patients with hypertension visiting cardiovascular clinics in Amman were approached randomly to participate in the study. The total number of patients who agreed to participate was 100, from which $69 \%$ were females; age range was 24 - 87 years, with average $50.8 \pm 12.25$ years (mean $\pm \mathrm{SD}$ ). All participants had doctor diagnosed hypertension and most of them (96\%) reported that their hypertension was responding to their current treatment.

Main reasons provided by the patients who declined from participating in the study were 


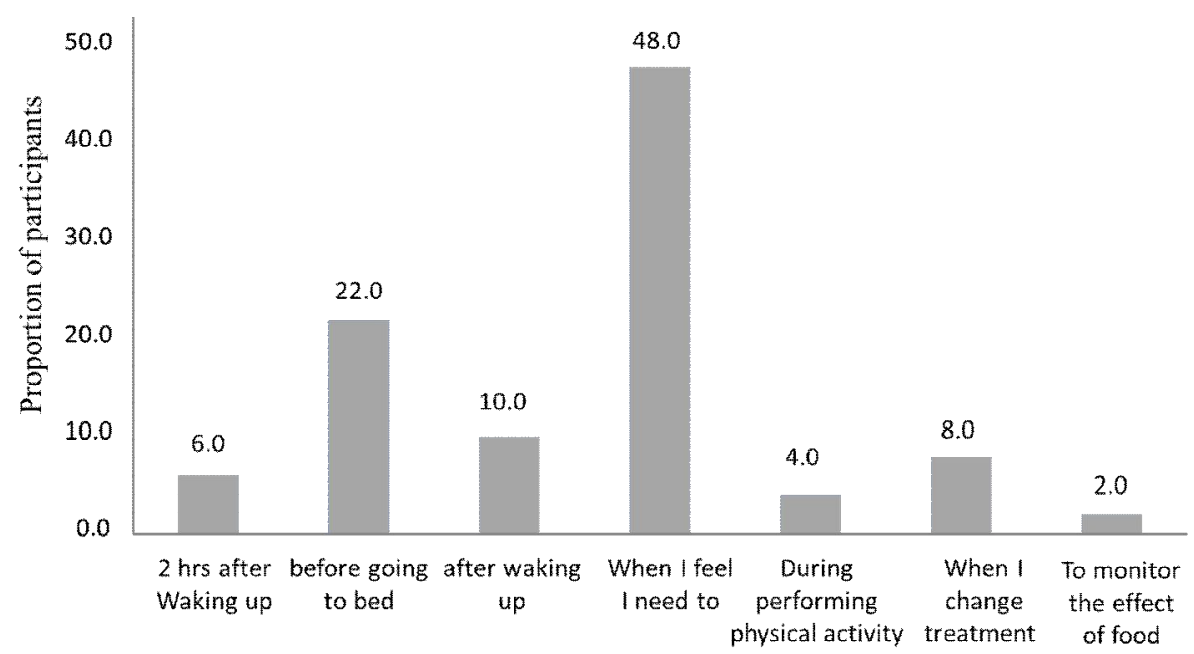

Figure 1: Proportion of patients $(n=100)$ reporting the times they measured their blood pressure at home

been busy, not interested, and rejecting to sign the consent form.

Majority of the participants (82.0\%) were using blood pressure home measuring monitors to monitor their blood pressure readings at home and to assess their response to treatment. The highest proportion of participants (51.2 \%) reported using the monitors once weekly and the rest were using them daily ( $30.5 \%$ once a day, $13.4 \%$ twice a day and $4.9 \%$ three times a day). Majority of participants (48\%) reported using the device "when they felt they needed to", $22 \%$ used monitors before going to bed, and others reported using the monitors after walking, when their medications were changed, after waking up, during physical activity, or to monitor the effect of certain food (Figure 1).

For the $18 \%$ of participants who do not use blood pressure at home using BP monitors, the reasons include anxiety $(66.7 \%)$, were not advised on their use $(22.2 \%)$, and prefer the pharmacist to do the blood pressure measurement (11.1\%).

Participants managed their high blood pressure readings by increasing physical activity (40\%), adjusting salt intake ( $24 \%$ ), adjusting medication dose $(10 \%)$ and contacting a health care professional (10 \%). Some patients (16\%) reported they did not take any action.

Regarding the effect of using home measuring monitors on the psychological status of the participants, $16 \%$ of the participants reported extreme anxiety, $52 \%$ reported some sort of anxiety, $32 \%$ reported no anxiety when their blood pressure readings were out of the normal ranges.
The majority of the participants (60\%) reported discussing their blood pressure readings with the specialist, followed by $26 \%$ of them discussing their readings with the pharmacist, $12 \%$ with the nurse and $2 \%$ with the general practitioner.

The pharmacist was reported by the majority of patients as the health care professional responsible for counseling them on the proper use of the blood pressure home measuring monitors $(50 \%)$. Others chose the specialist (30 $\%)$, nurse $(6 \%)$, general practitioner $(2 \%)$, while $12 \%$ reported more than one health care professional. Pharmacists were also reported as the health care professionals delivering the needed education on the suitable actions to be taken in response to the different blood pressure readings $(56 \%)$. The specialist came next in this regard (38\%), followed by the nurse $(4 \%)$ and the general practitioner $(2 \%)$.

\section{DISCUSSION}

Considering the high proportion of Jordanians suffering from hypertension, and the importance of using the blood pressure home measuring monitors, this study comes to reveal important information regarding patients' use of these monitors and role of the health care professionals in Jordan. Previous studies conducted in Jordan showed that only $30 \%$ of hypertensive patients achieved controlled blood pressure values, with the majority of them not achieving proper blood pressure goals [2]. Hence, the importance of the current study lies in significant relevant information reported that could be employed in conducting educational programs and awareness campaigns aiming to increase disease control [13]. 
Patient's awareness regarding the use of blood pressure home measuring monitors was found high in this study, as majority of the participants (82\%) were using the monitors to measure their blood pressure at home. Regular home blood pressure monitoring is a good indicator towards better compliance and hence disease control $[7,8]$. However, in response to high blood pressure readings, only $20 \%$ of participants in this study adjusted their medication dose or contacted a health care professional. The level of patient involvement in their treatment have been said to be essential in obtaining goal blood pressure [14]. Failure to take the needed antihypertensive medication results in higher incidence of disease progression and stroke rates [15]. Hence, it is vital to provide hypertensive patients with individual action plans from their physicians clarifying what they need to do in response to the high blood pressure readings they acquire from their monitors.

The main reason reported by the non-users of blood pressure home measuring monitors in this study was anxiety about using these monitors at home, which is not surprising considering the strong association between hypertension and anxiety [16]. Most patients reported feeling anxiety when their blood pressure measurements showed high readings, clarifying the significant impact this procedure has on the psychological status of the patients. In the doctor's office, anxiety also leads to white-coat-effect on blood pressure measurements, which has been associated with a higher degree of cardiovascular abnormalities [16]. Hence, educational programs targeting patients who suffer anxiety from using these monitors are necessary.

There is current evidence of the beneficial effects of moderate physical activity on the arterial stiffness and on overall clinical outcomes of patients with hypertension [17]. Only $40 \%$ of the participants in this study reported performing some type of physical activity when their blood pressure readings were high. The acute effect of physical activity on blood pressure readings is also important. It was found that a single bout of aerobic exercise reduced $24 \mathrm{~h}$ ambulatory blood pressure levels in long-term-treated hypertensive patients and increased the percentage of patients reaching normal ambulatory blood pressure values [17]. Aerobic exercise also has a potential role in blood pressure management of long-term-treated hypertensive both in active and sedentary obese hypertensive patients [18].

Other meta-analysis studies [19] found that diet is more important than exercise. Effect of exercise, diet and combination of both on blood pressure showed that exercise is significantly less effective than diet in lowering blood pressure. Only $24 \%$ of the patients in this study reduced their salt intake when they obtained high blood pressure readings. Importance of low salt diet for hypertensive patients has been very well known since the 1950s as strong evidence showed that salt restriction is an effective antihypertensive strategy [19].

Previous research has highlighted opportunities for clinical pharmacists to adopt a role in supporting the use of blood pressure home measuring monitors [20]. Pharmacists are in a pivotal position for providing pharmaceutical care services including measurements of blood pressure, education on the medical condition and medication use. In this study, the pharmacist was identified as the health care professional to counsel patients on the proper use of the blood pressure home measuring monitors (56\%), followed by the specialist. We recommend collaborative practice models between pharmacists and physicians as they have been found to optimize medication management and lead to improvements in hypertension outcomes [20].

\section{Limitations of the study}

The study was conducted in Amman, the city of Jordan, and hence results may not reflect the situation in other parts of Jordan, since most of the specialist physicians who provide the most skilled health care are located in the capital. Although presence of any mental disorder was an exclusion criterion, accurate patient medical history was not available, as specialists were not directly involved in this study. In Jordan, it is difficult to acquire an accurate patient medical history, due to the fact that patients visit different specialists for each medical condition, and a general practitioner/family doctor does not play a significant role in the country as in the developed countries. A larger sample size for this cross sectional study would have provided more generalized results, however recruitment of patients with hypertension was a difficult and time consuming process. Similar future studies need to provide a longer period of time for patient recruitment to reach the needed sample size.

\section{CONCLUSION}

Majority of the hypertensive patients in Amman, Jordan are using the blood pressure home measuring monitors, mostly on a once-weekly basis. Actions taken in response to high blood pressure readings involved mainly physical

Trop J Pharm Res, November 2014; 13(11):1950 
activity and reduction in salt intake. Few patients contacted a health care professional in response to abnormal high blood pressure readings. Majority of patients reported feeling anxious when their blood pressure readings were outside of their normal ranges. Pharmacists are the health care professionals patients seek most for education on the use of these monitors. A public health awareness campaign highlighting the value of the blood pressure home measuring monitors and role of the pharmacists in this area is strongly recommended.

\section{ACKNOWLEDGEMENT}

The authors acknowledge Sinan Al-Hindi and Manal Ayash (both pharmacists) for their assistance during the study. They are grateful to the Applied Science University, Amman, Jordan, for the financial support granted to cover the publication fee of this research article.

\section{REFERENCES}

1. Lackland DT. Hypertension: Joint National Committee on Detection, Evaluation, and Treatment of High Blood Pressure guidelines. Curr Opin Neurol. 1097; 26(1): 8-12.

2. Jaddou HY, Bateiha AM, Ajlouni KM. Prevalence, awareness and management of hypertension in a recently urbanised community, eastern Jordan. J Hum Hypertens. 2000; 14(8): 497-501.

3. World Health Organization (WHO). Regional health systems observatory report. [cited 2014 July 14]. Available from http://gis.emro.who.int/HealthSystemObservatory/PD F/Jordan/Full\%20Profile.pdf

4. Shishani K, Dajani R, Khader Y. Hypertension risk assessment in the largest ethnic groups in Jordan. $J$ Immigr Minor Health. 2007; 15(1): 43-48.

5. Al-Safi SA, Aboul-Enein FH, Aboul-Enein BH, Manuel B. Influence of family history and lifestyle on blood pressure and heart rate in young adults in Jordan. Public Health. 2006; 120(11): 1027-1032.

6. Khoury SA, Massad D, Fardous T. Mortality and causes of death in Jordan 1995-96: assessment by verbal autopsy. Bull World Health Organ. 1999; 77(8): 641650.

7. Takahashi H, Yoshika M, Yokoi T. Validation of home blood pressure-monitoring devices, Omron HEM1020 and Omron i-Q132 (HEM-1010-E), according to the European Society of Hypertension International Protocol. Blood Press Monit. 2011; 16(4): 203-207.

8. Nakano $H$, Kikuya $M$, Hara A, Nakashita $M$, Hirose $T$, Obara $T$, Metoki $H$, Inoue R, Asayama K, Ohkubo T, Totsune $K$, Imai $Y$. Self-monitoring of ambulatory blood pressure by the Microlife WatchBP 03--an application test. Clin Exp Hypertens. 2011; 33(1): 3440.

9. Celis H, Den Hond E, Staessen JA. Self-measurement of blood pressure at home in the management of hypertension. Clin Med Res. 2005; 3(1): 19-26.

10. Verberk WJ, Kroon AA, Kessels AG, de Leeuw PW. Home blood pressure measurement: a systematic review. J Am Coll Cardiol. 2005; 46(5): 743-751.

11. Bancej CM, Campbell N, McKay DW, Nichol M, Walker $R L$, Kaczorowski J. Home blood pressure monitoring among Canadian adults with hypertension: results from the 2009 Survey on Living with Chronic Diseases in Canada. Can J Cardiol. 2010; 26(5): 5257.

12. Internet World States. [cited 2012 May 15]. Available from http://www.internetworldstats.com/

13. Kearney PM, Whelton M, Reynolds K, Whelton PK, He J. Worldwide prevalence of hypertension: a systematic review. J Hypertens. 2004; 22(1): 11-19.

14. Neutel JM, Smith $D H$. Improving patient compliance: a major goal in the management of hypertension. J Clin Hypertens (Greenwich). 2003; 5(2): 127-132.

15. Prevention of stroke by antihypertensive drug treatment in older persons with isolated systolic hypertension. Final results of the Systolic Hypertension in the Elderly Program (SHEP). SHEP Cooperative Research Group. JAMA. 1991; 265(24): 3255-3264.

16. Penzo M, Guzzardi G, Palatini P. Relationship between blood pressure determination anxiety and hypertensive complications. Cardiologia. 1995; 40(2): 117-122.

17. O'Donovan C, Lithander FE, Raftery T, Gormley J, Mahmud A, Hussey J. Inverse Relationship Between Physical Activity and Arterial Stiffness in Adults with Hypertension. J Phys Act Health. 2013; 28: 28.

18. Taylor-Tolbert NS, Dengel DR, Brown MD, McCole SD, Pratley RE, Ferrell RE, Hagberg JM. Ambulatory blood pressure after acute exercise in older men with essential hypertension. Am J Hypertens. 2000; $13(1$ Pt 1): 44-51.

19. Fagard RH. Effects of exercise, diet and their combination on blood pressure. J Hum Hypertens. 2005; 19(Supp/ 3): S20-24.

20. Ernst ME. Ambulatory blood pressure monitoring: recent evidence and clinical pharmacy applications. Pharmacotherapy. 2013; 33(1): 69-83. 